УДК 556.3; 551.4

\title{
УХУДШЕНИЕ СИТУАЦИИ С ПОДТОПЛЕНИЕМ, СВЯЗАННОЕ С АНТРОПОГЕННЫМ ВЛИЯНИЕМ НА ПРИМЕРЕ ГОРОДА ТЮКАЛИНСКА
}

\author{
Медведков Кирилл Станиславович ${ }^{12}$, \\ kmedvedkov@mail.ru \\ Штриплинг Лев Оттович², \\ los@omgtu.ru \\ 'АО «Омская геологоразведочная экспедиция», \\ Россия, 644007, г. Омск, ул. Гусарова, 16. \\ 2 Омский государственный технический университет, \\ Россия, 644050, г. Омск, пр. Мира, 11.
}

Актуальность работы обусловлена увеличением влияния антропогенного фактора в развитии процессов подтопления освоенных территорий. В последние годы в Омской области подтоплению подвергается большое количество населенных пунктов, в том числе и местности с благополучными в целом условиями. Одним из таких населенных пунктов является город Тюкалинск, где проблема подтопления серьезно ощущалась в последние четыре года, что и повлияло на выбор объекта исследования.

Цель работы: выявление причин обострения ситуации с подтоплением, поиск решений по стабилизации проблемы с учетом влияния реки, осуществляющей естественный дренаж территории.

Методы исследования: анализ многолетних наблюдений за подземными водами на скважинах режимной сети мониторинга состояния недр с учетом количества выпавших осадков, выявление причинно-следственных связей с использованием графоаналитических зависимостей.

Результаты. Проанализированы многолетние изменения уровня подземных вод, разгрузка которых осуществляется в реку Тюкалка. Изучена интенсивность выпавших осадков на данной территории за периоды обследований. Выявлены причины медленного ухода талых вод весной и накопления подземных вод в многолетний период. Несмотря на достаточно высокую упругость приходно-расходного баланса (атмосферные осадки - поверхностные - подземные воды) и высокую способность к отводу избыточной воды за счет транзитной (пересекающей город) реки Тюкалка, многочисленные антропогенные сооружения, такие как: водопроводящие трубы, плотины, насыпные мосты, дороги и мн. др., вносят существенный вклад в естественный дренаж, понижая расходную часть водного баланса. Регулирование стока реки приводит к ухудшению отвода как поверхностных, так и подземных вод, увеличивая риски развития подтопления и продолжительность весеннего половодья.

\section{Ключевые слова:}

Подземные воды, антропогенное влияние, разгрузка, подтопление, половодье,

режим, скважина, наблюдения, уровень подземных вод, поверхностные воды, атмосферные осадки.

Город Тюкалинск - административный центр Тюкалинского района Омской области, расположенный на востоке Ишимской равнины на реке Тюкалка, в 124 км к северо-западу от областного центра - города Омска.

К настоящему моменту население города составляет порядка 11,2 тысяч человек [1]. В последнее время (с 2013 г.) одной из проблем местных жителей является подтопление территории, приуроченное $к$ весеннему половодью. Несмотря на то, что населенный пункт обеспечен естественным дренажем в виде реки Тюкалка, она не успевает отводить большой объем воды, а талые и подземные воды приводят к подтоплению обширных территорий города и окрестностей. Пик половодья приходится на второй квартал (с апреля по июнь). Для оценки ситуации и возможных причин возникновения столь сильного половодья и приуроченного к нему подтопления (в последние годы) авторами были использованы материалы, полученные в ходе исследования реки, данные по количеству выпадающих осадков и режимным наблюдениям по скважине № 275 . Скважина № 275 , данные по которой фиксируются ТЦ ГМСН (АО «ОГРЭ»), нахо- дится в районе метеостанции города и оборудована фильтром в водоносных слоях верхнего миоцена (7,8-15,7 м) (рис. 1), в 1,5 км на северо-запад от нее протекает река Тюкалка.

Режим подземных вод исследуемой местности относятся к приречному (прибрежному), что характеризует тесную гидродинамическую связь системы «поверхностные - подземные воды», вызывая существенные отклонения в водном балансе, при изменении приходной или расходной части в одной или другой составляющей «системы». При этом фиксация уровня подземных вод (более инертной составляющей системы) с учетом количества выпадающих осадков позволяет оценивать изменения в водном балансе и строить прогнозы его изменения.

С учетом сказанного выше, были проанализированы колебания уровня подземных вод за весь период с начала режимных наблюдений. Важность данных, получаемых в ходе режимных наблюдений по скважинам, широко отражена во многих литературных источниках [2-8]. Данные о поведении уровня подземных вод приведены на графике (рис. 2). 


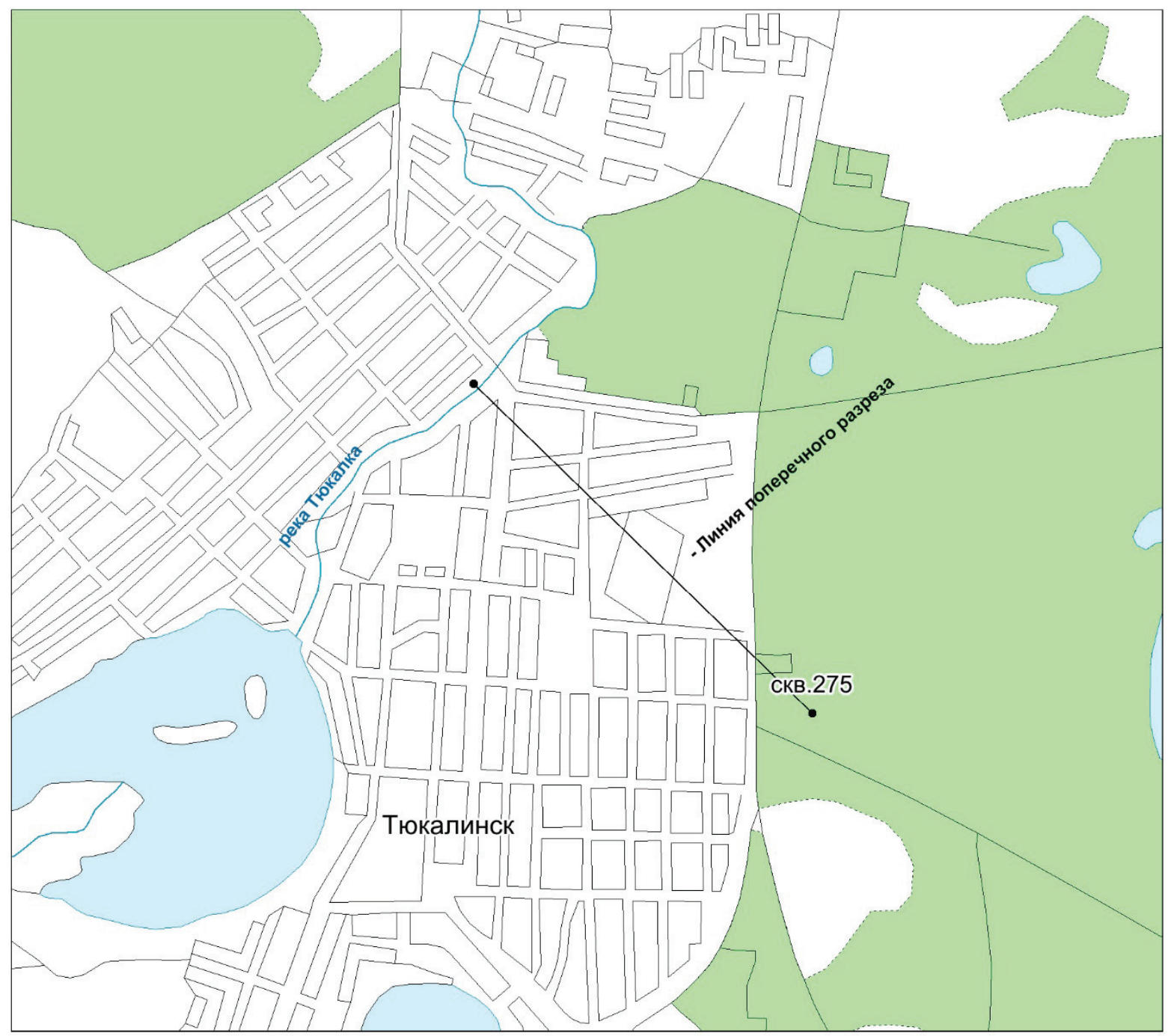

Масштаб 1:25 000

Рис. 1. Гидрогеологическая скважина № 275, оборудованная на первый от поверхности водоносный горизонт

Fig. 1. Hydrogeological well no. 275 , equipped at the first aquifer from the surface

Как видно из графика, имеется практически циклическая зависимость (уровень-дата) с повторяющимся пиками минимума и максимума, которая характеризуется близкой к горизонтальной линией тренда (прямолинейная линия тренда построена средствами электронных таблиц Excel). Также стоит отметить, что правая часть графика (с 2012 г.) выходит за рамки привычного колебания уровня и достаточно «круто» устремляется вверх, что может говорить о накоплении подземных вод в поровом пространстве водоносного горизонта и подъеме уровня подземных вод к поверхности, обусловленном уменьшением расхода подземных вод или увеличением приходной части водного баланса.

Рассматривая данные о положении уровня воды в реке (03.09.14 и 02.06.15) в сопоставлении с уровнями подземных вод за аналогичные даты в скважине № 275 (рис. 3), можно заметить, что в реке уровень ниже на 1,27 и 1,88 м $(09.14$ и
06.15 соответственно). А максимальный уровень, характерный для половодья, будет около 113 м (в Балтийской системе высот, для 1 \% обеспеченности), что практически исключает подпитку «подземных вод наблюдательной скважины» речными водами. Кроме того, полученные уровни воды и ярко выраженная сезонность колебаний уровней в скважине (максимумы характерны для времени весеннего снеготаянья и выпадения обильных осадков) дополнительно подтверждают наличие подземного питания реки Тюкалка, тесную связь подземных и поверхностных вод на исследуемом участке. Следует отметить, что геологическое описание пород, вскрытых скважиной № 275 , приведено схематично, в виду отсутствия первичных материалов, буровых журналов и подробной документации по данной скважине. Фильтр скважины № 275 оборудован в водоносных слоях верхнего миоцена (7,8-15,7 м), представленных прос- 


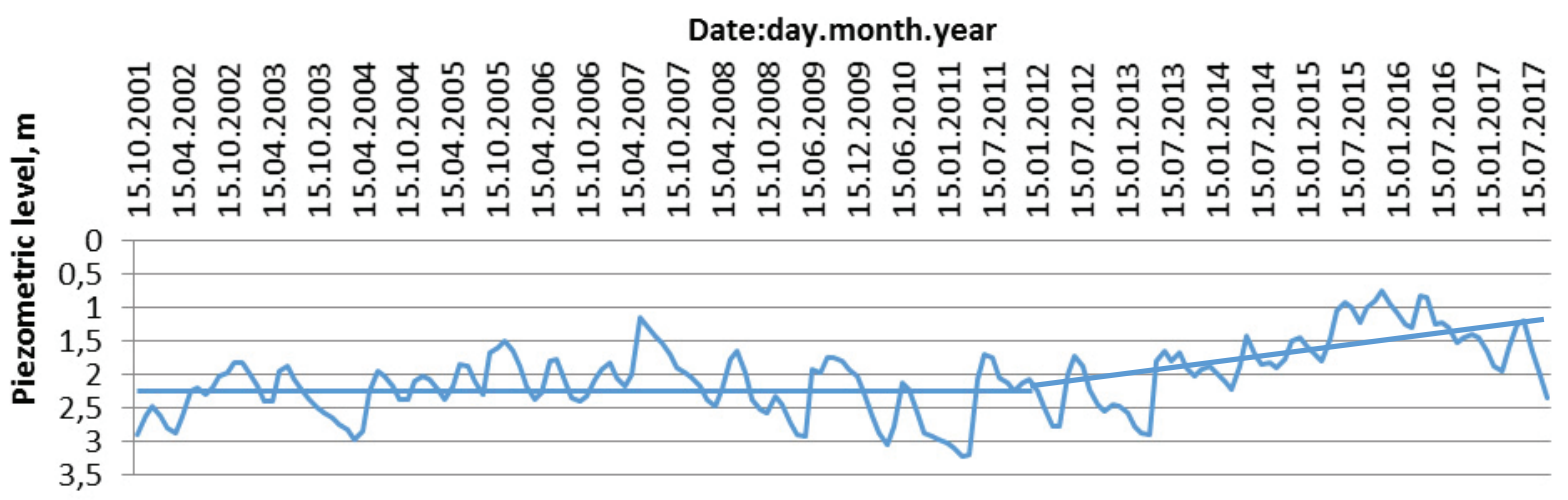

Рис. 2. Изменение уровня подземных вод в скважине № 275 (за весь период наблюдений)

Fig. 2. Fluctuations in groundwater level of well no. 275 (for the entire period of observation)

лаиванием суглинка с песком, рабочая часть его располагается в интервале 10,4-12,7 м. Кровля водоносного горизонта представлена преимущественно суглинками. Ввиду того, что расстояние между наблюдательной скважиной и рекой составляет 1,5 км, представленный поперечный разрез ограничен лишь профилем реки и разрезом непосредственно по скважине с соблюдением вертикального масштаба высот согласно шкале.

Учитывая данные по абсолютным отметкам Балтийской системы высот для района расположения скважины - это порядка 114 м, и в районе жилой застройки вблизи реки Тюкалка (в сторону которой происходит разгрузка подземных вод) это около 113 м, можно сказать, что наблюдатель- ная скважина служит индикатором риска подтопления города. При повышении уровня в скважине до отметки менее 1 м (более 113 м по абсолютным отметкам) с учетом уклона пьезометрической поверхности в сторону реки (около 0,001$)$ происходит опасная ситуация, при которой могут подтапливаться как подземные, так и надземные сооружения. В период половодья ситуация приближается к критической за счет уменьшения стока подземных вод в реку и инфильтрации поверхностных вод, приводящих к стремительному повышению уровня подземных (в том числе и грунтовых) вод, - в следствии чего подтоплению могут подвергаться значительные по площади территории города.
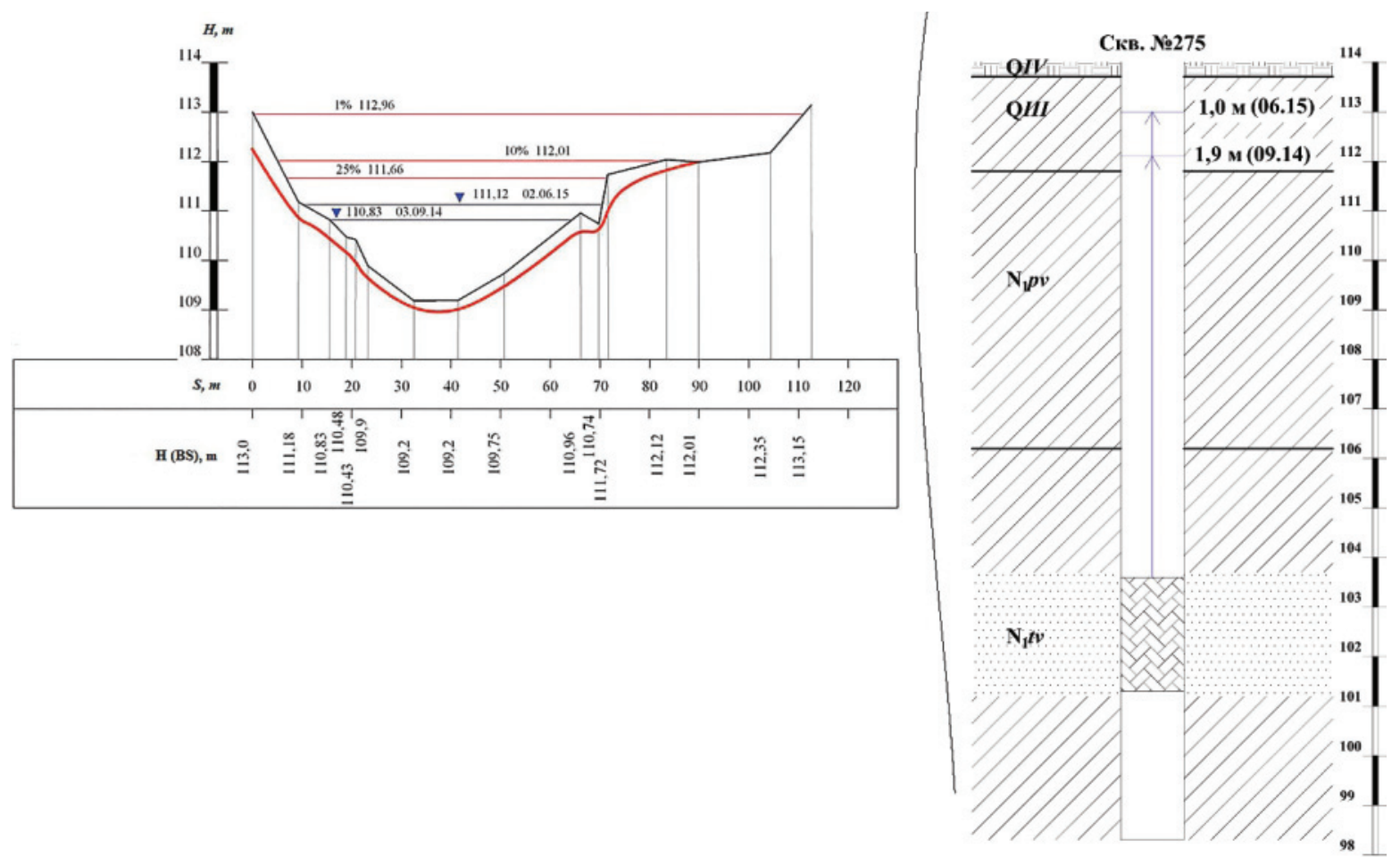

Рис. 3. Поперечный разрез по реке Тюкалка и скважине № 275

Fig. 3. Cross-section along the Tyukalka River and well no. 275 


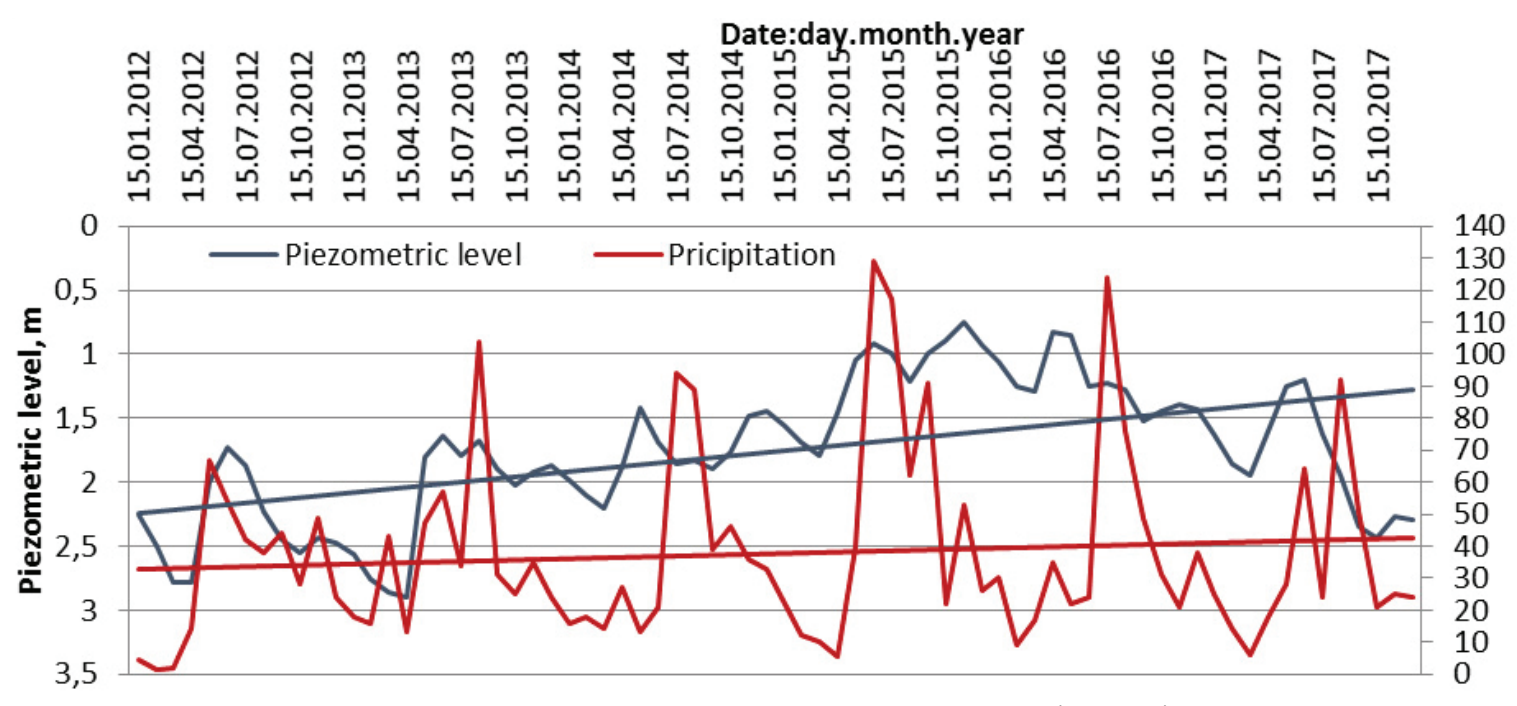

Рис. 4. Количество осадков и изменение уровня подземных вод в скважине № 275 (с 2012 г.)

Fig. 4. Precipitation and fluctuations in the level of groundwater of the well no. 275 (from 2012)

Необходимо отметить, что в целом в городе Тюкалинск отмечалась довольно стабильная ситуация, связанная с развитием процессов подтопления, которые если и были, то носили локальный и кратковременный характер. График на рис. 2 показывает, что уровень подземных вод в наблюдательной скважине не поднимался выше $1,5 \mathrm{~m}$ (за двумя редкими исключениями) до 2012 г. С 2012 г. начинается стабильный подъем уровня, который в 2015-2016 гг. стабильно превышал отметку в 1 м, что параллельно сопровождалось подтоплением городской территории.

Для более детального анализа повышения уровня подземных вод с начала 2012 г. были проанализированы данные по уровням совместно с количеством выпавших осадков [9] за одинаковые промежутки времени. Построен график, охватывающий по времени последние 6 лет наблюдений (рис. 4).

Как видно из графика, за последние шесть лет в уровне подземных вод произошли значительные изменения. Так, линия тренда в начале периода наблюдений (рис. 4) характеризуется уровнем в 2,25 м от земли, но к концу 2017 г. приближается к отметке 1,25 м (без учета понижения уровня воды в скважине начиная с 2016 г.). В то же время линия тренда суммы выпавших за месяц осадков показывает рост с 32 до 42 мм, что несопоставимо с величиной подъема уровня подземных вод. Расчеты показывают, что при пористости водовмещающих пород, равной 0,1 , увеличение осадков на 10 мм не должно привести к повышению уровня подземных вод более чем на 100 мм. Отсюда следует, что существенные изменения в водном балансе не могут произойти только за счет увеличения интенсивности атмосферных осадков.

С учетом того, что существенная часть подземных вод (первых от поверхности водоносных горизонтов) разгружается в транзитную для города ре- ку Тюкалка, тенденция к повышению уровня подземных вод может быть связана с уменьшением пропускающей способности водотока, связанного с наличием на реке множества инженерных сооружений IV класса [10], напрямую влияющих на скорость течения и объем транзита воды.

Река Тюкалка относится к водотокам с весеннелетним половодьем и дождевыми паводками в тёплое время года. В питании реки участвуют талые воды сезонных снегов, жидкие атмосферные осадки и подземные воды. Главным источником питания являются твёрдые атмосферные осадки, основная фаза водного режима представлена весеннелетним половодьем. Весенний подъём уровня начинается в середине-конце апреля. Наивысшие уровни наблюдаются в конце апреля - начале мая. В период половодья проходит 60-80 \% годового стока. Летне-осенняя межень наступает к концу июня. Выпадающие осадки обуславливают некоторый подъём уровней, дождевые паводки не характерны, лишь в многоводные годы они составляют примерно 30 \% стока во время весеннего паводка. В маловодные годы река в верховье пересыхает. Зимняя межень устанавливается с середины октября. Это самый продолжительный и маловодный период водного режима [11].

C учетом вышесказанного можно сделать вывод, что основное воздействие на подтопление территории города Тюкалинск в апреле-мае оказывают талые воды, с транзитом которых не справляется река Тюкалка. Кроме этого, как уже было отмечено выше, во время половодья снижается объем разгрузки подземных вод в реку (уменьшается гидравлический уклон потока подземных вод), что приводит к подъему уровня подземных вод и дополнительно способствует подтоплению территории Тюкалинска. Кроме того, график (рис. 4) показывает, что на протяжении 2015-2016 гг. повы- 


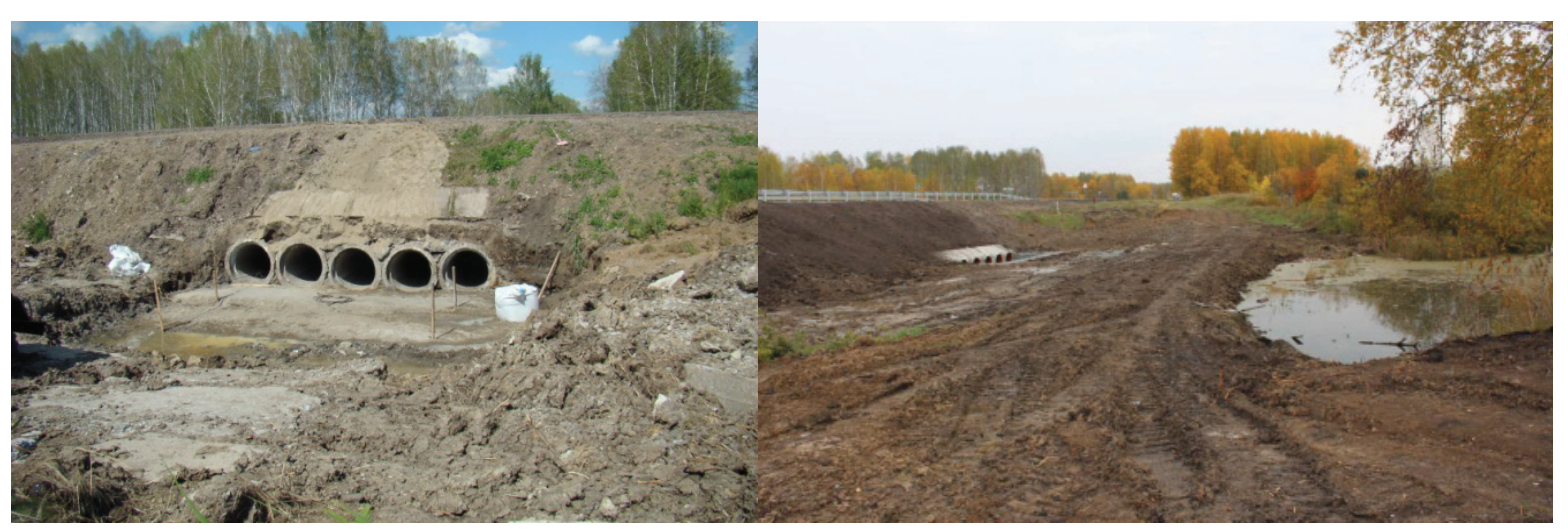

Рис. 5. Грунтовая плотина на р. Тюкалка и водопропускные трубы через автомагистраль по состоянию на 2014 г. (слева - июль 2014 г., справа - сентябрь 2014 г.)

Fig. 5. Soil dam on the river Tyukalka and culverts across the highway (on the left - July 2014, on the right - September 2014)

шенные уровни подземных вод наблюдались и в несвойственные для половодья периоды времени. Все это может говорит о том, что изменился естественный режим разгрузки подземных вод, и причины нужно искать в антропогенном воздействии на условия поверхностного и подземного стока.

Основные проблемы с активным проявлением процессов подтопления вблизи города Тюкалинска возникли с 2013 г. [12-14].

Специалистами АО «ОГРЭ» в 2014-2015 гг. проведены наблюдения на реке Тюкалка, которые позволили выявить многочисленные рукотворные сооружения, препятствующие естественному стоку реки. Часть из них и вовсе не позволяла воде пройти (рис. 5).

Как видно из рисунка, путь реке преграждает грунтовая плотина, не дающая воде продолжить свой путь по руслу. Данное сооружение снижает не только пропускную способность реки, скорость которой на момент обследования практически отсутствует, но и воздействует на естественный сток подземных вод, снижая расходную часть баланса.

Анализ данных космических снимков сверхвысокого разрешения в районе пересечение трассы

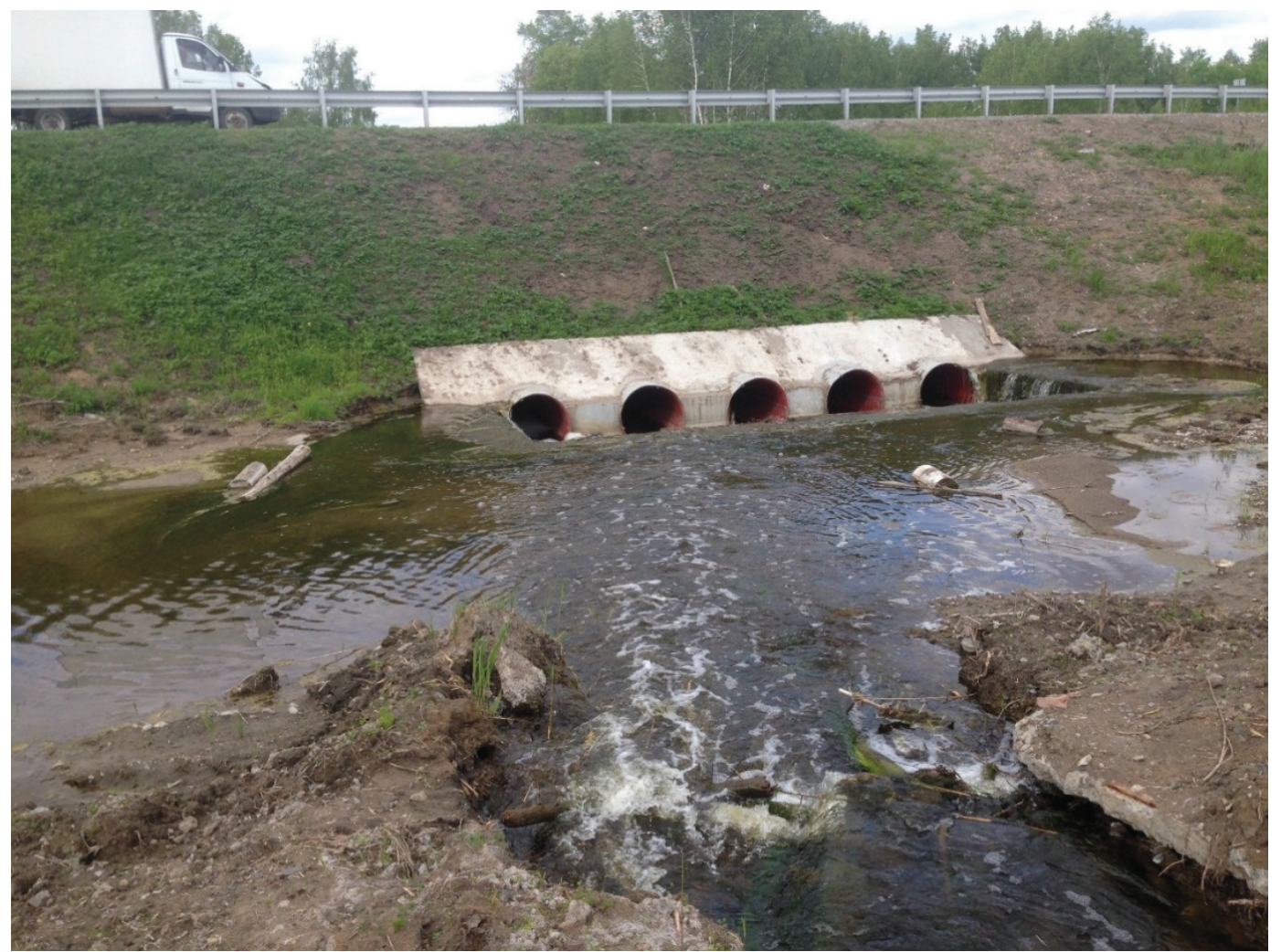

Рис. 6. Грунтовая плотина на р. Тюкалка и водопропускные трубы через автомагистраль по состоянию на июль 2015 г.

Fig. 6. Soil dam on the river Tyukalka and culverts across the highway (July 2015) 
Тюмень-Омск рекой Тюкалка показывает, что течение реки «прерывалось» искусственной дамбой и ранее - 10.08.2012 и 17(22).08.2013.

В июле 2015 г. при повторном обследовании было обнаружено, что дамба вскрыта, река имеет течение 0,5 м/с (рис. 6).

Влияние восстановления движения водного потока реки можно проследить на примере графиков изменения уровней подземных вод, с учетом выбора интервалов с июня по октябрь (периоды максимального водообмена, атмосферные осадки-поверхностные-подземные воды без учета сезона половодья), когда река полностью справляется с потоком поступающих вод и полноценно выполняет роль естественной дрены (рис. 7).

Питание реки в выбранные месяцы в основном происходит за счет разгрузки подземных вод и выпадающих атмосферных осадков. Данные, представленные на графике (рис.7), позволяют сделать вывод о восстановлении разгрузки ближе к концу 2015 г. (рис. 4, 7) при снижении общего уровня подземных вод в районе города Тюкалинск, что может быть связано со вскрытием дамбы, которая затрудняла путь реке еще с 2012 г.

Очевидно, что тесная взаимосвязь подземных вод и поверхностного стока реки оказывает существенное влияние на формирование подтопления в городе. Учитывая то, что через русло р. Тюкалки оборудовано множество переездов с дренажными устройствами, так или иначе влияющими на течение реки, - данные сооружения оказывают влияние и на подземные воды, разгрузка которых затрудняется и происходит их накапливание с дальнейшим повышением уровня. Тренд, показывающий их рост, отчетливо прослеживается начиная с 2012 г. Влияние гидротехнических сооружений на ситуацию с подтоплениями отмечено многими авторами $[15,16]$.

В соответствии с СП 11-105-97 часть II, подтопление в городе Тюкалинск развивается вслед- ствие подъема уровня первого от поверхности водоносного горизонта, который испытывает существенные сезонные и многолетние колебания [17]. Подтопление усугубляется весенним половодьем, снижающим интенсивность разгрузки подземных вод и приводящим к увеличению их уровня, что и происходит в период с мая по июнь (рис. 2).

На основании данного утверждения, в соответствии с постановлением правительства Российской Федерации № 360 от 18 апреля 2014 г. «Об определении границ зон затопления, подтопления», paйон расположения наблюдательной скважины № 275 и существенную часть города Тюкалинска можно отнести к территории умеренного подтопления - при глубине залегания подземных вод до 2 м от поверхности [18].

Для уменьшения рисков подтопления в городе Тюкалинск необходимы меры по регулированию течения реки Тюкалка, которые бы способствовали транзиту больших масс воды во время весеннего половодья и осуществляли естественный дренаж подземных вод первых от поверхности водоносных горизонтов, снижая риск развития процессов подтопления. Ключевая роль дренажа в ситуации с увеличением уровня подземных вод отмечается во многих литературных источниках [19-21].

\section{Выводы}

Рассматривая полученные данные по гидрогеологической скважине № 275 , оборудованной на подземные воды верхнего миоцена вблизи города Тюкалинска, и материалы по обследованию р. Тюкалка с учетом интенсивности атмосферных осадков, можно прийти к следующим заключениям:

1. Наличие многолетних наблюдений за подземными водами с учетом данных по сумме атмосферных осадков позволяет выявлять зависимости приходно-расходных составляющих водного баланса, естественные природные колебания с сезонными пиками и спадами, тренд хода уровня

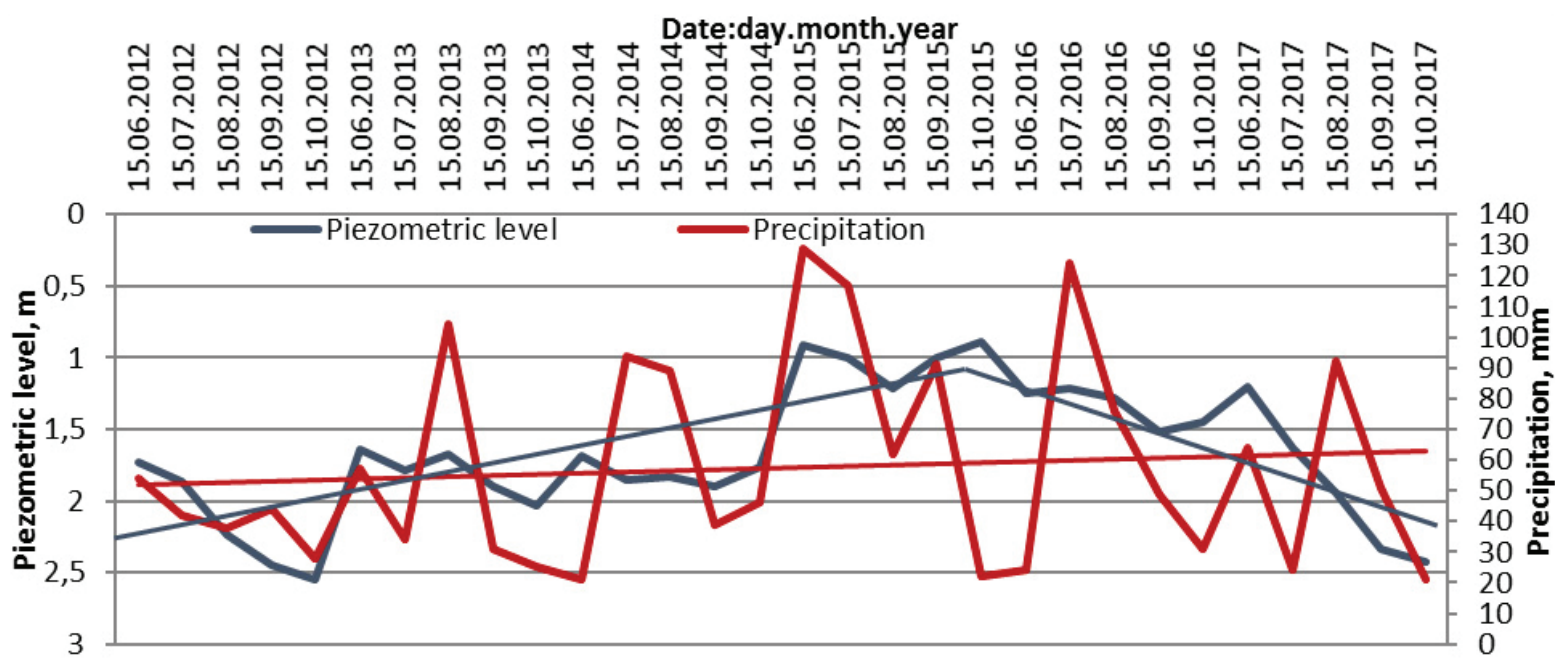

Рис. 7. Количество осадков и изменение уровня подземных вод скважины № 275 (за июнь-октябрь начиная с 2012 г.)

Fig. 7. Precipitation and fluctuations in the level of groundwater of the well no. 275 (June-October since 2012) 
подземных вод и давать общую оценку ситуации на локальных участках, приводящих к развитию процессов техногенного подтопления. Мониторинг подземных вод является важным инструментом, позволяющим определять степень риска потенциальной подтопляемости территории.

2. Выявление аномальных отклонений колебания уровня подземных вод (время смены направления линии тренда) без существенного изменения уровня атмосферных осадков позволяет определять причины данных отклонений, анализ которых дает возможность обосновать проектирование природоохранных мероприятий. Так, анализируя многолетние наблюдение за уровнем воды в скважине № 275, можно отметить:

- активизация подтопления (в первую очередь во время весеннего половодья) в районе города Тюкалинск с большой долей вероятности связана с наличием на реке Тюкалка большого количества инженерных сооружений, препятствующих естественному стоку и влияющих на водный баланс;

\section{СПИСОК ЛИТЕРАТУРЫ}

1. Федеральная служба государственной статистики (Росстат). Численность населения Российской Федерации по муниципальным образованиям на 1 января 2016 года. - М.: Росстат, 2017. $-584 \mathrm{c}$.

2. Korbel K.L., Hose G.C. The weighted groundwater health index: Improving the monitoring and management of groundwater resources // Ecological Indicators. - April 2017. - V. 75. - P. 164-181. URL: http://dx.doi.org/10.1016/j.ecolind.2016.11.039 (дата обращения: 11.01.2017).

3. Assessment of trends in groundwater levels across the United States / Tess Russo, Upmanu Lall, Hui Wen, M. Williams // Columbia Water Center White Paper. March 2014. URL: http://water.columbia.edu/files/2014/03/USGW_WhitePaper_FINAL.pdf (дата обращения: 11.01.2017).

4. Miller C., Mork L. Whychus Creek Restoration Project at Camp Polk Preserve. 2014 Groundwater Monitoring Report. Upper Deschutes Watershed Council Bend, Oregon November, 2014. URL: http://www.upperdeschuteswatershedcouncil.org/wp-content/uploads/2013/08/20141106-CP-Groundwater-MonitoringReport-FINAL.pdf (дата обращения: 11.01.2017).

5. Chapter 6. Groundwater responses due to various MAR structures: Case studies from Chennai, Tamil Nadu, India / Raicy Mani Christy, Parimalarenganayaki Sundaram, Thirunavukkarasu Munuswamy, Thomas Lutz, Michael Schneider and Lakshmanan Elango // Natural Water Treatment Systems for Safe and Sustainable Water Supply in the Indian Context. 2015. - P. 99-112. URL: https: / / zenodo.org/record / 61088 / files / 9781780408392_6.pdf (дата обращения: 05.02.2017).

6. Investigation of rootzone salinity with field monitoring system at tsunami affected rice fields in Miyagi, Japan / Ieyasu Tokumoto, Katsumi Chiba, Masaru Mizoguchi, Hideki Miyamoto // Manuscript under review for journal SOIL. Published: 18 March 2016. URL: http://www.soil-discuss.net/soil-2016-12/soil2016-12.pdf (дата обращения: 05.02.2017).

7. Roberts R. HydroResolutions, LLC. East Torrance Soil and Water Conservation District. Evaluation of Groundwater Level Data from Estancia Basin. January 2012. URL: http://ebwpc.org/ PDFS/Evaluation_of_Groundwater_Level_Data_from_Estancia_Basin_Monitoring_Wells.pdf (дата обращения: 11.01.2017).
- увеличение риска подтопления в последние годы происходит и в несвойственные для населенного пункта летне-осенние периоды, что связано с общим повышением уровня подземных вод;

- высока вероятность того, что в последние годы подтопление развивается из-за наличия на пересечении с трассой Тюмень-Омск плотины у реки Тюкалка;

- анализ данных по количеству атмосферных осадков подтвердил их минимальный вклад в повышение уровня подземных вод за последние годы;

- отсутствие должных усилий по налаживанию дренажной системы города Тюкалинска и грамотного регулирования стока реки Тюкалка может привести к появлению глобальной проблемы с половодьем (в том числе и с летне-осенними паводками) и подтоплениям территории в целом, что ранее было практически не свойственно территории данного населенного пункта.

8. Янкович Е.П., Янкович А.С. Информационная среда для эколого-геохимической оценки состояния подземной гидросферы // Интерэкспо Гео-Сибирь. - 2012. - № 3. URL: http://cyberleninka.ru/article/n/informatsionnaya-sreda-dlya-ekologo-geohimicheskoy-otsenki-sostoyaniya-podzemnoy-gidrosfery (дата обращения: 20.01.2017).

9. Архив погоды в Тюкалинске. URL: https://rp5.ru/Аpхив_погоды_в_Тюкалинске_дата обращения: 21.06.2018).

10. СНиП 33-01-2003. Гидротехнические сооружения. - М.: Госстрой России, 2004. -28 с.

11. Кузнецов М.Ю. и др. Отчет по объекту: «Проведение мониторинговых исследований дна и берегов реки Тюкалка Тюкалинского муниципального района от оз. Разлив до оз. Кошара». Омск, АО «ОГРЭ», 2015. - 156 с.

12. Подтопление - процесс управляемый // Тюкалинский вестник. - 6 сентября 2013. - № 36. URL: http://tukalinsk.ru/View.asp? objType $=2 \&$ objValue $=76760 \&$ rnd $=02645776053116853$ (дата обращения: 15.10.2016).

13. Лосева Л. Когда весна не в радость // Тюкалинский вестник. 15 апрель 2016. - № 15. URL: http://tukalinsk.ru/View.asp? objType $=2 \&$ objValue $=87947 \&$ rnd $=07209831701924043$ (дата обращения: 15.10 .2016$)$.

14. Лосева Л. Ситуация под контролем власти // Тюкалинский вестник. - 22 апреля 2016. - № 16. URL: http://tukalinsk.ru $/$ View $\cdot$ asp objType $=2 \&$ objValue $=88017 \&$ rnd $=$ 07548072539927448 (дата обращения: 15.10.2016)

15. Разумова Н.В., Разумов В.В., Молчанов Э.Н. Переувлажнение и подтопление почв и земель в Центральном регионе России // Бюл. Почв. ин-та. - 2016. - № 82. URL: http://cyberleninka.ru/article/n/pereuvlazhnenie-i-podtoplenie-pochv-i-zemel-vtsentralnom-regione-rossii (дата обращения: 20.01.2017).

16. Esenov P.E., Starodubtsev V.M. Changes in soil-ameliorative conditions of the Tejen river delta. Modern directions of theoretical and applied researches. - March 2014. URL: http://www. sworld.com.ua/konfer34/104.pdf (дата обращения: 20.01.2017)

17. СП 11-105-97 «Инженерно-геологические изыскания для строительства». Ч. ІІ. - М.: Госстрой РФ, 2000. - 45 с.

18. Постановление Правительства РФ № $360.0 б$ определении границ затопления, подтопления. - М., 2014. - 8 с.

19. London Borough of Redbridge: Strategic Flood Risk Assessment. Level 2 Addendum. URL: https://www.redbridge.gov.uk/me- 
dia/2285/draft-strategic-flood-risk-assessment-level-2-addendum.pdf (дата обращения: 20.01.2017).

20. Environmental state and buffering properties of underground hydrosphere in waste landfill site of the largest petrochemical companies in Europe / R.Kh. Musin, N.A. Kurlyanov, Z.G. Kalkamanova, T.V. Korotchenko// IOP Conf. Series: Earth and Environmental Science. - 2016. № 33. - 012019. URL: http:// kpfu.ru/staff_files/F2037153077/EES_33_1_012019.pdf (дата обращения: 20.01 .2017$)$.
21. Медведков К.С., Штриплинг Л.0. Анализ подтопляемой территории на примере грунтовых вод города Называевска // Известия Томского политехнического университета. Инжиниринг георесурсов. - 2017. - T. 328. - № 4. URL: https://cyberleninka.ru/article/n/analiz-podtoplyaemoy-territorii-na-primere-gruntovyh-vod-goroda-nazyvaevska (дата обращения: 06.07.2017).

Поступила 30.8.2018 г.

\section{Информация об авторах}

Медведков K.С., аспирант кафедры промышленной экологии и безопасности Омского государственного технического университета, заместитель генерального директора по производству АО «Омская геологоразведочная экспедиция».

Штриплинг Л.О., доктор технических наук, профессор, заведующий кафедрой промышленной экологии и безопасности, проректор по учебно-методической работе Омского государственного технического университета. 
UDC 556.3; 551.4

\title{
DEGRADATION OF FLOODING SITUATION RELATED TO ANTHROPOGENIC EFFECTS ON THE EXAMPLE OF TYUKALINSK
}

\author{
Kirill S. Medvedkov ${ }^{1,2}$, \\ kmedvedkov@mail.ru \\ Lev 0. Shtripling², \\ los@omgtu.ru \\ ' Omsk Geological Expedition, \\ 16, Gusarov street, Omsk, 644007, Russia. \\ 2 Omsk State Technical University, \\ 11, Mira avenue, Omsk, 644050, Russia.
}

Relevance of the work is caused by the increase in the role of human factor in development of flooding areas. In recent years, in Omsk region spring flood exposed to a large quantity of settlements, including areas with satisfactory conditions. One of these settlements is Tyukalinsk where there are serious flooding problems in the last four years, that influenced the choice of the research object.

The aim of the study is to identify the causes of deterioration of spring flood situation, to search for solutions to flooding stabilization taking into account the presence of the river, carrying out the natural drainage area.

The methods: analysis of long-term observations of groundwater in the wells of regime subsurface condition of monitoring network taking into account the amount of precipitation, identification of graphical-analytical dependencies and causality.

Results. The authors have analyzed the long-term changes in groundwater levels, which enter into the river Tyukalka. They study the values of precipitation in the given territory for the periods of surveys. The causes of slow withdrawal of meltwater in spring and the accumulation of groundwater to the many years were identidied. Despite the relatively high elasticity of admission and expenditure parts of the water balance (precipitation - surface water - groundwater) and high capacity for allotment of excess water by transit (crossing the city) Tyukalka river, numerous man-made structures such as carrying water pipes, dams, bulk bridges, road and many others, contribute significantly to the natural drainage, reducing the expenditure side of water balance. Regulation of river flow leads to poor drainage of both surface and groundwater, increasing the risk of flooding and the duration of the spring flood.

\section{Key words:}

Groundwater, anthropogenic influence, unloading, flooding, high water, mode, well, observation, groundwater level, surface water, precipitation.

\section{REFERENCES}

1. Federalnaya sluzhba gosudarstvennoy statistiki (Rosstat). Chislennost naseleniya Rossiiskoy Federattsii po munitsipalnym obrazovaniyam na 1 yanvarya 2016 goda [The population of the Russian Federation for municipalities on January 1, 2016]. Moscow, Rosstat Publ., 2017. 584 p.

2. Korbel K.L., Hose G.C. The weighted groundwater health index: Improving the monitoring and management of groundwater resources. Ecological Indicators, April 2017, vol. 75, pp. 164-181. Available at: http://dx.doi.org/10.1016/j.ecolind.2016.11.039 (accessed 11 January 2017).

3. Tess Russo, Upmanu Lall, Hui Wen, Mary Williams. Assessment of trends in groundwater levels across the United States. Colum bia Water Center White Paper, March 2014. Available at: http://water.columbia.edu/files/2014/03/USGW WhitePaper FINAL.pdf (accessed 11 January 2017).

4. Miller C., Mork L. Whychus Creek Restoration Project at Camp Polk Preserve. 2014 Groundwater Monitoring Report. Upper Deschutes Watershed Council Bend, Oregon November, 2014. Available at: http://www.upperdeschuteswatershedcouncil.org/wp-content/uploads/2013/08/20141106-CP-Groundwater-Monitoring-Report-FINAL.pdf (accessed 11 January 2017).

5. Raicy Mani Christy, Parimalarenganayaki Sundaram, Thirunavukkarasu Munuswamy, Thomas Lutz, Michael Schneider and Lakshmanan Elango. Ch. 6. Groundwater responses due to various MAR structures: Case studies from Chennai, Tamil Nadu, India. Natural Water Treatment Systems for Safe and Sustainable Wa ter Supply in the Indian Context, 2015, pp. 99-112. Available at: https://zenodo.org/record/61088/files/9781780408392 6.pdf (accessed 05 February 2017).
6. Ieyasu Tokumoto, Katsumi Chiba, Masaru Mizoguchi, Hideki Miyamoto. Investigation of rootzone salinity with field monitoring system at tsunami affected rice fields in Miyagi, Japan. $M a$ nuscript under review for journal SOIL, 18 March 2016. Available at: http://www.soil-discuss.net/soil-2016-12/soil-2016-12.pdf (accessed 05 February 2017).

7. Roberts R. HydroResolutions, LLC. East Torrance Soil and Water Conservation District. Evaluation of Groundwater Level Data from Estancia Basin, January 2012. Available at: http:// ebwpc.org/PDFS/Evaluation_of_Groundwater_Level_Data from Estancia Basin Monitoring Wells.pdf (accessed 11 January 2017).

8. Yankovich E.P., Yankovich A.S. Informatsionnaya sreda dlya ekologo-geokhimicheskoy otsenki sostoyaniya podzemnoy gidrosfery [Information Environment for Ecological-geochemical assessment of the state of underground hydrosphere]. Interekspo Geo-Sibir 2012. No. 3. Available at: http://cyberleninka.ru/article/n/informatsionnaya-sreda-dlya-ekologo-geohimicheskoy-otsenki-sostoyaniya-podzemnoy-gidrosfery (accessed 20 January 2017).

9. Arkhiv pogody $v$ Tyukalinske [Weather archive in Tyukalinsk]. Available at: https://rp5.ru/Архив_погоды_в_Тюкалинске (accessed 21 June 2018).

10. SNiP 33-01-2003. Gidrotekhnicheskie sooruzheniya [Hydraulic structures]. Moscow, Gosstroi Russii, 2004. 28 p.

11. Kuznetsov M.Yu. Otchet po obektu: Provedenie monitoringooykh issledovaniy dna i beregov reki Tyukalka Tyukalinskogo munitsipalnogo rayona ot oz. Razliv do oz. Koshara [Report on the project: Monitoring studies of the bottom and banks of the river Tyukalka Tyukalinsk municipal area from the Razliv lake to the Koshara lake]. Omsk, OGRE Publ., 2015. 156 p. 
12. Podtoplenie - protsess upravliaemy [Flooding may be controlled]. Tyukalinsky vestnik, 6 September 2013, no. 36. Available at: http://tukalinsk.ru/View.asp?objType $=2 \&$ objValue $=$ $76760 \&$ rnd $=02645776053116853$ (accessed 15 October 2016).

13. Loseva L. Kogda vesna ne v radost [When the spring is not a joy]. Tyukalinsky vestnik, 15 April 2016, no. 15. Available at: http://tukalinsk.ru/View.asp?objType=2\&objValue= 87947\&rnd=07209831701924043 (accessed 15 October 2016).

14. Loseva L. Situatsiya pod kontrolem vlasti [The situation is under the control of authorities]. Tyukalinsky vestnik, 22 April 2016, no. 16. Available at: http://tukalinsk.ru/View.asp?objType $=2 \&$ objValue $=88017 \&$ rnd $=07548072539927448 \quad$ (accessed 15 October 2016).

15. Razumova N.V., Razumov V.V., Molchanov E.N. Pereuvlazhnenie i podtoplenie pochv i zemel v Tsentralnom regione Rossii [Waterlogging and flooding of soils and land in Central Russia]. Byulleten Pochvennogo instituta, 2016, no. 82. Available at: //cyberleninka.ru/article/n/pereuvlazhnenie-i-podtoplenie-pochv-i-zemel-v-tsentralnom-regione-rossii (accessed 20 January 2017).

16. Esenov P.E., Starodubtsev V.M. Changes in soil-ameliorative conditions of the Tejen river delta. Modern directions of theoretical and applied researches, March 2014. Available at: http://www.sworld.com.ua/konfer34/104.pdf (accessed $20 \mathrm{Ja}$ nuary 2017).
17. SP 11-105-97 Inzhenerno-geologicheskie izyskaniya dlya stroitelstva [Engineering survey for construction]. Moscow, Gosstroy RF, 2000. P. II, 45 p.

18. Postanovlenie Pravitelstva RF № 360 . Ob opredelenii granits $z a$ topleniya, podtopleniya [Determining the boundaries of flooding]. Moscow, 2014. 8 p.

19. London Borough of Redbridge: Strategic Flood Risk Assessment. Level 2 Addendum. Available at: https://www.redbridge.gov.uk/media/2285/draft-strategic-flood-risk-assessment-level-2-addendum.pdf (accessed 20 January 2017).

20. Musin R.Kh., Kurlyanov N.A., Kalkamanova Z.G., Korotchenko T.V. Environmental state and buffering properties of underground hydrosphere in waste landfill site of the largest petrochemical companies in Europe. IOP Conf. Series: Earth and Environmental Science, 2016, no. 33, 012019. Available at: http:// kpfu.ru/staff_files/F2037153077/EES_33_1_012019.pdf (accessed 20 January 2017).

21. Medvedkov K.S., Shtripling L.0. Analysis of flooded areas on the example of ground waters in Nazyvaevsk. Bulletin of the Tomsk Polytechnic University. Geo assets Engineering, 2017, vol. 328, no. 4. In Rus. Available at: https://cyberleninka.ru/article/n/analiz-podtoplyaemoy-territorii-na-primere-gruntovyhvod-goroda-nazyvaevska (accessed 06 July 2017).

Received: 30 August 2018.

\section{Information about the authors}

Kirill S. Medvedkov, postgraduate student, Omsk State Technical University; deputy director, Omsk Geological Expedition.

Lev 0. Shtripling, Dr. Sc., professor, head of the department, Omsk State Technical University. 